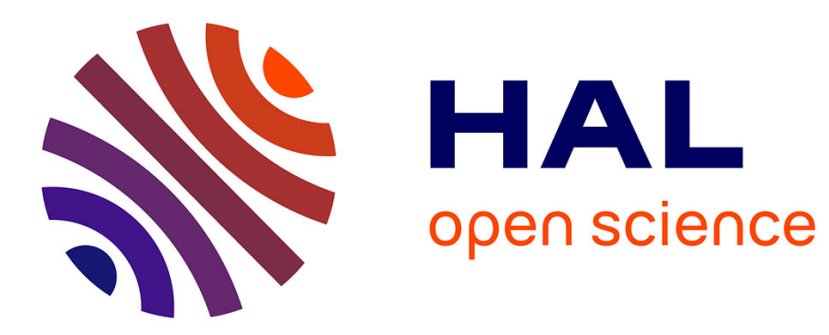

\title{
Electrical conductivity of microemulsions : a case of stirred percolation
}

\author{
M. Laguës
}

\section{To cite this version:}

M. Laguës. Electrical conductivity of microemulsions: a case of stirred percolation. Journal de Physique Lettres, 1979, 40 (14), pp.331-333. 10.1051/jphyslet:019790040014033100 . jpa-00231637

\section{HAL Id: jpa-00231637 https://hal.science/jpa-00231637}

Submitted on 1 Jan 1979

HAL is a multi-disciplinary open access archive for the deposit and dissemination of scientific research documents, whether they are published or not. The documents may come from teaching and research institutions in France or abroad, or from public or private research centers.
L'archive ouverte pluridisciplinaire HAL, est destinée au dépôt et à la diffusion de documents scientifiques de niveau recherche, publiés ou non, émanant des établissements d'enseignement et de recherche français ou étrangers, des laboratoires publics ou privés. 


\title{
Electrical conductivity of microemulsions : a case of stirred percolation $(*)$
}

\author{
M. Laguës \\ Laboratoire de Physique Quantique, E.S.P.C.I., 10, rue Vauquelin, 75231 Paris Cedex 05, France
}

(Reçu le 12 avril 1979, accepté le 5 juin 1979)

\begin{abstract}
Résumé. - La conductivité électrique $G$ de microémulsions - eau dans l'huile - présente un comportement de percolation [1] : en-dessous d'une concentration d'eau critique $\phi_{\mathrm{c}}$, la conductivité semble diverger comme $\left(\phi_{\mathrm{c}}-\phi\right)^{-S^{\prime}}$, tandis qu'au-dessus de $\phi_{\mathrm{c}}$ elle augmente comme $\left(\phi-\phi_{\mathrm{c}}\right)^{T^{\prime}}$. Dans cette situation physique que l'on peut qualifier de percolation brassée (par le mouvement Brownien du liquide) les exposants $S^{\prime}$ et $T^{\prime}$ n'ont a priori pas de raison d'être identiques aux exposants $S$ et $T$ de la situation classique de percolation gelée. Un modèle simplifié de percolation brassée rend compte de façon satisfaisante de l'exposant $S^{\prime}=1,2 \pm 0,1$, alors que la valeur admise pour $S$ est 0,7 . L'exposant $T^{\prime}$, dont la valeur mesurée varie de 1,4 à 1,6, est moins significatif pour la différence entre percolation gelée et brassée : Les valeurs prévues pour $S^{\prime}$ seraient environ 1,8 contre 1,6 pour $S$
\end{abstract}

\begin{abstract}
The electrical conductivity $G$ of water in oil microemulsions may be described by percolation models [1] : below a critical water concentration $\phi_{c}, G$ seems to diverge as $\left(\phi_{\mathrm{c}}-\phi\right)^{-s^{\prime}}$, while for $\phi>\phi_{\mathrm{c}} G$ increases as $\left(\phi-\phi_{\mathrm{c}}\right)^{-T^{\prime}}$. This physical situation may be called stirred percolation, referring to the Brownian motion of the medium. The exponents $S^{\prime}$ and $T^{\prime}$ are $a$ priori different from the corresponding $S$ and $T$ in the classical situation of frozen percolation. A simple model of stirred percolation accounts fairly well for the measured value of $S^{\prime}=1.2 \pm 0.1$ while the accepted value for $S$ is 0.7 . The exponent $T^{\prime}$ (1.4 to 1.6 in our experimental case) is less significant of the difference between stirred and frozen percolation : the values for $S^{\prime}$ should be about 1.8 and the value accepted for $S$ should be about 1.6.
\end{abstract}

1. Electrical conductivity of microemulsions. - We measured the electrical conductivity of microemulsions - water in oil - containing cyclohexan, sodium dodecyl sulphate (SDS) and 1 pentanol. The conductivity is extremely sensitive both to temperature and composition. The following procedure allowed a reproducibility of a few percent :

a) all the components, except a small quantity of alcohol, are introduced in the conductivity cell, the temperature of which is fixed at $20^{\circ} \mathrm{C} \pm 0.1{ }^{\circ} \mathrm{C}$,

b) the alcohol is added slowly while the conductivity is measured,

c) a maximum of conductivity is reached when the mixing clears up to make a microemulsion. This value is the conductivity of the microemulsion containing the minimum of alcohol which provides stability.

A suitable dilution procedure allows $\phi$ to be varied while the structure of droplets remains fixed [2].

(*) La version française sera publiée dans le $\mathrm{n}^{\circ} 20$ des C.R.A.S., série B, du 28 mai 1979.
We studied two different types of microemulsions characterized by a volumic ratio, soap to water, in the droplets :

$$
\begin{array}{ll}
\text { type A } & \mathrm{s} / \mathrm{w}=0.69 \\
\text { type B } & \mathrm{s} / \mathrm{w}=0.345 .
\end{array}
$$

The conductivity increases steeply (five orders of magnitude) around a critical concentration $\phi_{\mathrm{c}}$. The variation above $\phi_{\mathrm{c}}$ allows an independent determination of $T$ and $\phi_{\mathrm{c}}$ :

$G^{1 / T^{\prime}} \sim\left(\phi-\phi_{\mathrm{c}}\right)$ is linear in $\phi$ and tends to zero at $\phi=\phi_{\mathrm{c}}$.

The plot of $G^{1 / x}$ for different values of $x$ has opposite concavities when $T$ is greater or smaller than $T^{\prime}$ (Fig. 1). The results for the three types of microemulsions are presented in table I.

When the water concentration is very low $(\phi<0.01)$ the conductivity is linear in $\phi$, in agreement with a conduction mechanism involving the migration of charged droplets [1]. The percolation contribution to $G$ is thus obtained by $G_{\mathrm{p}} \sim G / \phi$. Figure 2 presents 


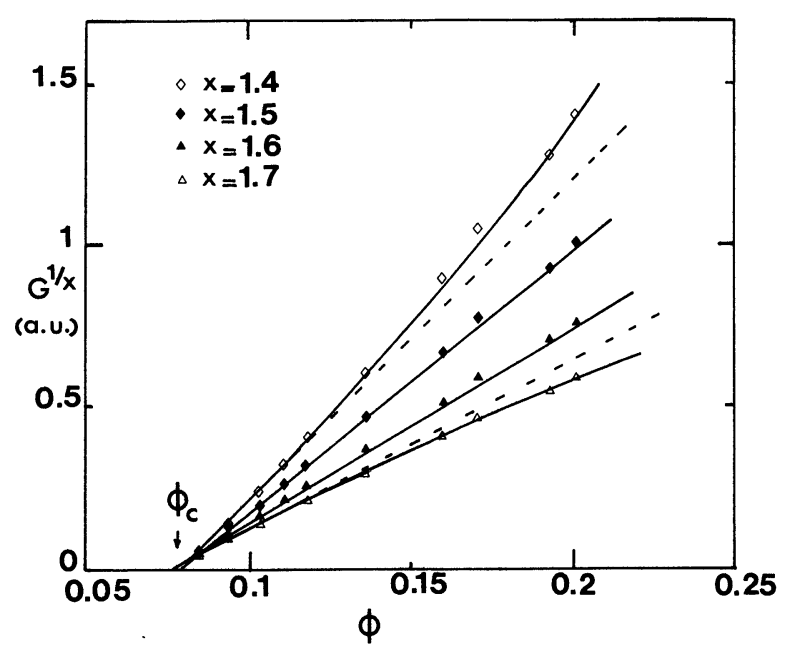

Fig. 1. - Determination of the exponent $T^{\prime}$ and of the critical water concentration $\phi_{\mathrm{c}}$, for $\phi>\phi_{\mathrm{c}}: G^{1 / x}$ is plotted for various $x$ values as a function of $\phi$.

Table I. - Exponents $T^{\prime}$ and $S^{\prime}$ measured for microemulsions of different soap/water ratios.

$\begin{array}{ccc}\text { Microemulsion } & \text { A } & \text { B } \\ - & - & - \\ \frac{\text { Soap }}{\text { Water }} & 0.69 & 0.345 \\ T^{\prime} & 1.6 \pm 0.1 & 1.55 \pm 0.1 \\ S^{\prime} & 1.28 \pm 0.1 & 1.08 \pm 0.1\end{array}$

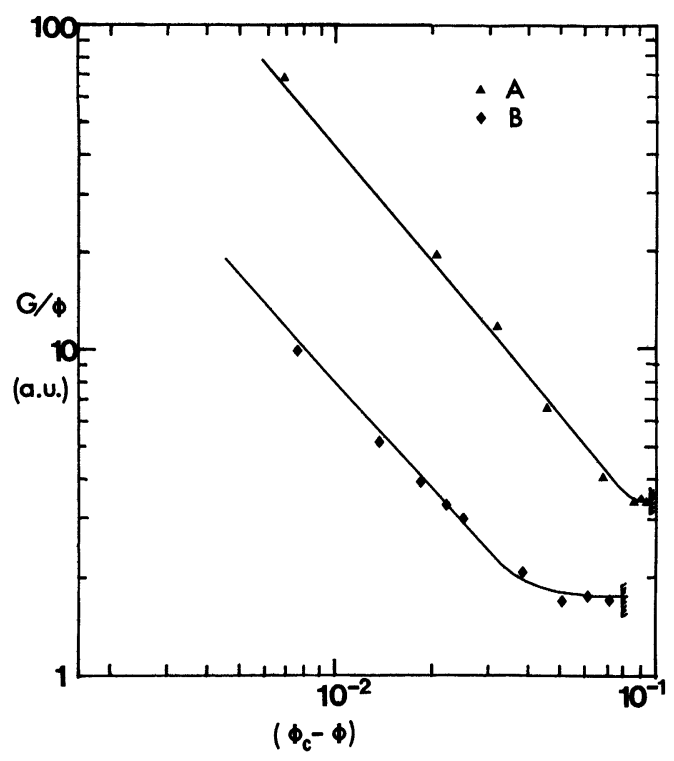

Fig. 2. - The conductivity of a microemulsion for $\phi<\phi_{\mathrm{c}}$ is plotted versus $\left(\phi_{\mathrm{c}}-\phi\right)$. Two different ratios soap/water are presented (see text).

$\log (G / \phi)$ versus $\log \left(\phi_{\mathrm{c}}-\phi\right)$ for the three types of microemulsions. In each case, the slope is not much different of 1.2 (Table I).
2. A model for stirred percolation. - The electrical conductivity $G$ of an insulating solid containing conductive particles is described by frozen percolation. $G$ is very low if the concentration $\phi$ is lower than a critical value $\phi_{\mathrm{c}}$ at which an infinite path through the conductive particles appears. Around and above this concentration, $G$ inereases steeply.

Essam et al. have suggested that $G^{\prime}$ behaves in the vicinity of $\phi_{\mathrm{c}}$ as [3]

$$
\begin{array}{ll}
\phi<\phi_{\mathrm{c}} & G=G_{0}\left(\phi_{\mathrm{c}}-\phi\right)^{-S} \\
\phi>\phi_{\mathrm{c}} & G=G_{1}\left(\phi-\phi_{\mathrm{c}}\right)^{T}
\end{array}
$$

where $S$ and $T$ are independent of the physical details. Computer simulations $[4,5,6]$ and theoretical calculation $[7,8]$ give the following values for a $3 \mathrm{D}$ system :

$$
\begin{aligned}
& S=0.5 \text { to } 0.78 \\
& T=1.5 \text { to } 2.0 .
\end{aligned}
$$

Measured values of $T$ on different physical systems are in the range 1.4 to 2 , in agreement with the theory (A review of principal results is presented in reference [9]) while G. Deutscher and M. L. Rappaport measured $S=0.7$, for the conductivity of Al-Ge films [10].

When the conductive particles are suspended in a fluid, the stirred percolation case, the conductivity may behave very differently. In the following model, conductive particles move with a diffusion coefficient $D$ and they are assumed to interact through a hardsphere type potential. A cluster which exists at time will disappear after the time $t+\tau_{\mathrm{R}}$ and reorder in different clusters. The time $\tau_{\mathbf{R}}$ is of the order of :

$\tau_{\mathrm{R}} \sim a^{2} / D$ where $a$ is the radius of particles, whatever the $\left(\phi-\phi_{\mathrm{c}}\right)$.

To account for the kinetics of charge migration, we use a lattice with nodes connected by two types of conductances, a high one $\sigma_{+}$(probability $\phi$ ) and a low one $\sigma_{-}$(probability $1-\phi$ ), each node being grounded through a capacitance $C$. The potential $V_{i}$ at node $i$ satisfies

$$
C \frac{\partial V_{i}}{\partial t}=\sum_{j} \sigma_{i j}(t)\left(V_{i}-V_{j}\right)
$$

which is formally identical to the diffusion equation of a species at concentration $V_{i}$ with a jump frequency

$$
W_{i j}=\frac{\sigma_{i j}}{C}=\frac{1}{\theta_{i j}} .
$$

The conductivity $G$ is thus formally identical to the diffusion coefficient $\bar{D}_{\mathbf{v}}$ of this species.

We define two times $\theta_{+}$and $\theta_{-}$, corresponding to $\sigma_{+}$ and $\sigma_{-}$:

* $\theta_{+}$is the (short) migration time of charges in a conducting cluster :

$$
\theta_{+}=\frac{C}{\sigma_{+}} f(\phi) .
$$


* $\theta_{-}$is the (long) migration time of charges between large clusters in the frozen case :

$$
\theta_{-}=\frac{C}{\sigma_{-}} g(\phi) .
$$

To calculate $g$, we use the variation of $G$ in the frozen case :

and

$$
G \sim\left(\phi_{\mathrm{c}}-\phi\right)^{-S}
$$

$$
G \sim \bar{D}_{\mathrm{v}} \sim\left(\frac{\overline{R_{\mathrm{G}}^{2}}}{\theta_{-}}\right) \quad\left(\text { if } \theta_{+} \ll \theta_{-}\right)
$$

where $R_{\mathrm{G}}$, the gyration radius of the clusters, increases as $[8,11]$

$$
\overline{R_{\mathrm{G}}^{2}} \sim\left(\phi_{\mathrm{c}}-\phi\right)^{\beta-2 v}
$$

with $\beta$ and $v$ having the common definition.

The variation of $\theta_{-}$is thus :

$$
\theta_{-} \sim\left(\phi_{\mathrm{c}}-\phi\right)^{S+\beta-2 v} \text {. }
$$

The time $\theta_{-}$thus diverges when $\phi \rightarrow \phi_{\mathrm{c}}$, with an exponent

$$
2 v-S-\beta \sim 0.6
$$

3. Different situations. - Depending on the values of $\theta_{+}, \theta_{-}$and $\tau_{\mathbf{R}}$, three cases appear :

a) $\theta_{+} \ll \theta_{-} \ll \tau_{\mathrm{R}}$

is the frozen case :

$$
G \sim \frac{\overline{R_{\mathrm{G}}^{2}}}{\theta_{-}} \sim\left(\phi_{\mathrm{c}}-\phi\right)^{-S} .
$$

b) $\tau_{\mathrm{R}} \ll \theta_{+} \ll \theta_{-}$

is the completely stirred case. $G$ is the mean between $G_{+}(\phi=1)$ and $G_{-}(\phi=0)$ :

$$
G=\phi G_{+}+(1-\phi) G_{-}
$$

and it increases linearly with $\phi$. c) $\theta_{+} \ll \tau_{\mathrm{R}} \ll \theta_{-}$

is the mixed case, always existing near $\phi_{c}$, because $\theta_{-}$ diverges when $\phi \rightarrow \phi_{\mathrm{c}}$. The migration of charges between large clusters does not depend anymore on $\theta_{-}$ but only on $\tau_{\mathbf{R}}$. One may then assume that

$$
G \sim \frac{\overline{R_{\mathrm{G}}^{2}}}{\tau_{\mathrm{R}}} \sim\left(\phi_{\mathrm{c}}-\phi\right)^{\beta-2 v}
$$

and in three dimensions the exponent will be :

$$
S^{\prime}=2 v-\beta \sim 1.2 \text {. }
$$

This value is also the value of $S$ for a space dimension $d \geqslant 4[11]$.

For $\phi>\phi_{\mathrm{c}}$, the exponent $T^{\prime}$ measured for microemulsions are not very different from the accepted value for $T \sim 1.6$.

A theoretical guess of $T^{\prime}$ could be obtained in assuming the same scaling law that for $S^{\prime}$ : one could extrapolate at $d=3$ the law obtained by A. S. Skal and B. I. Shklovskii [12]

$$
T=1+v(d-2)
$$

which should give $T^{\prime}=1.84$ in three dimensions. An experimental check would thus be difficult in view of the small difference between $T$ and $T^{\prime}$.

4. Conclusion. - We suggest here a simplified description of the intricate behaviour of stirred percolation. Three different cases appear depending on the reordering time $\tau_{R}$ of the clusters. If $\tau_{R}$ is very large, the results of frozen percolation apply. If $\tau_{R}$ is much shorter than the typical times $\theta_{+}$and $\theta_{-}$of charge migration in and between the clusters, the conductivity is the mean between the conductivities of both phases. When $\tau_{\mathbf{R}}$ has an intermediate value between $\theta_{+}$and $\theta_{-}$, we assume that only the size of clusters accounts for the divergence of $G$ for $\phi<\phi_{\mathrm{c}}$.

This assumption agrees fairly with the measured conductivity of microemulsions for $\phi<\phi_{\mathrm{c}}$.

Acknowledgments. - We are indebted to P. G. de Gennes and C. Taupin for useful information.

\section{References}

[1] Laguës, M., Ober, R., Taupin, C., J. Physique Lett. 39 (1978) L-487.

[2] Dvolä̈tzky, M., Guyot, M., Laguës, M., Lepesant, J. P., Sauterey, C., Taupin, C., J. Chem. Phys. 69 (1978) 3279.

[3] Essam, J. W., Place, C. M. et Sondheimer, E. H., J. Phys. C 7 (1974) L-258.

[4] Kirkpatrick, S., Rev. Mod. Phys. 45 (1973) 574.

[5] Webman, I., Jortner, J., Cohen, M. H., Phys. Rev. B 11 (1975) 2885

[6] Straley, J. P., Phys. Rev. B 15 (1977) 5733.

[7] Fisch, R., Harris, A. B., Phys. Rev. B 18 (1978) 416.
[8] Stephen, M. J., Phys. Rev. B 17 (1978) 4444.

[9] Clarke, P. S., Orton, J. W., Guest, A. J., Phys. Rev. B 18 (1978) 1813.

[10] Deutscher, G., Rappaport, M. L., Proceedings of the 15th International Conference on Low Temperature Physics (L.T. 15), J. Physique Colloq. 39 (1978) C 6-581.

[11] De Gennes, P. G., C. R. Hebd. Séan. Acad. Sci. 286B (1978) 131

[12] Skal, A. S., ShkLovskiI, B. I., Sov. Phys. Semicond. 8 (1975) 1029. 